\title{
Comments on the article "Coronary artery fistula: a huge conus branch aneurysm"
}

\author{
dr med. Ireneusz Haponiuk \\ Department of Pediatric Cardiac Surgery, Mikołaj Kopernik Hospital in Gdańsk, Poland
}

Kardiochirurgia i Torakochirurgia Polska 2014; 11 (4): 444

The authors report an interesting case of an adult patient with a coronary anomaly who underwent successful operative treatment. The presented morphology of coronary fistula with the effect of coronary 'aneurysm' was doubly unique because of its origin from the conal branch of the right coronary artery. Congenital anomalies of coronary arteries are usually diagnosed early in childhood and can be an important, sometimes complicating factor in patients with various congenital heart defects. While asymptomatic the anomalies are diagnosed incidentally or during cardiac procedures for different indications in children [1]. It is natural that cardiac symptoms in adulthood are usually regarded as more typical for coronary artery disease or complex cardiovascular problems than as an effect of coronary anomalies. Nevertheless, following the report of Moodi F. with co-authors, it is worth keeping in mind that this rare pathology could also be a principal problem for patients at any age.

The authors report a patient who underwent diagnostics and surgical treatment after de novo 4-month long symptoms of progressive dypnea, probably as a clinical manifestation of heart insufficiency, although in the report it is not clearly explained if the patient had any prior cardiac symptoms or interventional history before admission. Currently the role of transthoracic two dimensional echocardiography with color Doppler in the diagnostics of an adult patient with pathological cardiac mass is essential. Nevertheless, l'll stress my cardiologist much more about the impact of the aneurysm on cardiac function, valvular flow patterns and the EF. There is some doubt whether the coronary angiogram could be completely normal in the presented individual. I would also be interested in the Qp/Qs ratio to assess the left-to-right shunt caused by the fistula. Modern computed tomography and cardiac magnetic resonance imaging could be useful methods to show more precisely the margins and the extent of the aneurysm before the operation.

The procedure of surgical excision of the aneurysm with cardiopulmonary bypass was reasonable, especially in the setting of unclear entry and the opening of the fistula [2]. I would definitely follow the decision and surgical strategy of the authors.
While the evaluation of the manuscript I made a brief analysis of patients with coronary anomalies in the experience of the Department of Pediatric Cardiac Surgery, Mikołaj Kopernik Hospital in Gdańsk. In the total of more than 1600 pediatric cardiac procedures performed after the $1^{\text {st }}$ of January 2008, anomalies of coronary arteries were diagnosed mostly in right heart lesions (ToF, PA), transpositions of the great arteries and an isolated anomalous left coronary artery from the pulmonary artery. Our goal is to diagnose precisely any coronary anomalies prior to the surgery to prevent any unexpected problems and improve the results, so angiography remains the gold standard in case of any doubts. In the outpatient group there are children with small isolated coronary fistulas who are regularly monitored because of murmurs. Our strategy is to postpone any interventional or surgical treatment unless their cardiac function remain in the normal range. In the pediatric group there is undoubtedly a great role for percutaneous transcatheter embolization techniques as first choice interventions [3], although the full spectrum of surgery and hybrid treatment is available in our heart team [4].

Finally, it is my great pleasure to recommend to Prof. Marian Zembala, Editor in Chief, and the Committee, the manuscript untitled "Coronary artery fistula: a huge conus branch aneurysm (case report)" for publication in the "Polish Journal of Cardiac and Thoracic Surgery".

\section{References}

1. Skalski JH, Haponiuk I. Przetoki i anomalie tętnic wieńcowych. In: Chirurgia naczyń wieńcowych. Zembala M, Bochenek A, Woś S (eds.). Wydawnictwo Lekarskie PZWL, Warszawa 2002; pp. 285-292.

2. Swan $\mathrm{H}$, Wilson $\mathrm{JH}$, Woodwark G. Surgical obliteration of a coronary artery fisula to right ventricle. Arch Surg 1959; 79: 820.

3. Mavroudis C, Backer CL, Rocchini AP, Muster AJ, Gevitz M. Coronary artery fistulas in infants and children: a surgical review and discussion of coil embolization. Ann Thorac Surg 1997; 63: 1235-1242.

4. Haponiuk I, Chojnicki M, Jaworski R, Steffens M, Szofer-Sendrowska A, Juściński J, Kwaśniak E, Szymanowicz W, Gierat-Haponiuk K, Leszczyńska K. Hybrid cardiovascular procedures in the treatment of selected congenital heart disease in children: a single-centre experience. Kardiol Pol 2014; 72 : 324-330. 